\title{
Redesigning Wastewater Infrastructure to Improve Resource Efficiency
}

\author{
Tove A. Larsen
}

Eawag, Swiss Federal Institute of Aquatic Science and Technology, 8600 Dübendorf, Switzerland (E-mail: larsen@eawag.ch)

\begin{abstract}
Resource efficiency of wastewater management is a question of optimizing at the same time the management of resources in wastewater (e.g. water), the resources spent on treatment and transport (e.g. energy), the natural resources to protect (e.g. the receiving waters), and the anthropogenic resources (e.g. capital). For instance, wastewater can be treated to any given quality, but only at the expense of energy and investment costs. Today, many up-coming problems are solved incrementally, leading to resource consuming solutions optimized for water pollution control in well off countries, whereas large parts of the world have at the best very simple wastewater treatment. From a global point of view, a system change is necessary in order to solve the immense problems arising from global population growth, urban development and climate change. Source separation is a promising concept for resource efficient wastewater management, but a more concerted effort is necessary from the international community in order to develop competitive technologies and overcome the inflexibility of the present end-of-pipe technology. Much more research and development are necessary, not only in the area of engineering, but also with respect to the socio economic dimensions, especially in the area of regulation, suitable governance and management models, and concerning the involvement of industrial partners.
\end{abstract}

Keywords:

global, wastewater, source separation, acceptance, compliance, resources, urine

\section{INTRODUCTION}

Worldwide, there is increasing concern about inadequate access to clean water and sanitation services. These concerns attracted international attention with the famous 'Dublin Statements' (UN Documents, 1992), and even more with the water and sanitation relevant issues contained in the Millennium Development Goals, adopted by the United Nations in the year 2000 (http://www.un. org/millenniumgoals/). Obviously, the main problems are found in the developing world, where even basic drinking water and sanitation services are not available. However, the environmental degradation caused by untreated wastewater from a growing (urbanized) world population is also an issue. Despite these pressing global problems, the gap between research on water and wastewater relevant technologies for the 'first' and 'third' world has remained. Generally speaking, the former concentrates on ever increasing sophistication of existing centralized systems, whereas the latter is mainly concerned with simple technology for water provision and basic sanitation requirements of a poor, predominantly rural population.

With rapid population growth and climate change, it is becoming clearer that it will be difficult to solve global problems of water availability, sanitation and water pollution control with the existing model of centralized urban water management systems. Whereas some authors see the solutions in more advanced science and technology for water and wastewater purification (e.g. Shannon et al., 2008), a number of wastewater professionals have started questioning the ruling end-of-pipe paradigm, even in western industrialized countries (e.g. Guest et al., 2009; Larsen et al., 2009). Despite the very different approaches in these three papers, a common denominator is the concern 
about resource efficiency and effective solutions for the water crisis. This concern also has consequences for rich industrialized countries and is reflected in the wastewater related part of the 2010 IWA Leading Edge Conference in Phoenix, where resource efficiency was a main topic. The present paper is based on a broad resource understanding originally presented by Larsen and Gujer (1997) and illustrated in Figure 1. It argues that measures taken early in the system (i.e. at or before the generation point of an actual waste(water) stream), and at the same time minimizing mixing and dilution of the different streams, will generally be more effective and resource efficient than end-ofpipe measures. One may thus term this concept 'source control and source separation'. It has been investigated for diffuse sources as illustrated by heavy metals and biocides (e.g. Burkhardt et al., 2007) as well as for point sources as illustrated by the technology of urine source separation (also termed NoMix technology; Larsen and Gujer, 1996; Larsen et al., 2001; Larsen et al., 2009; see also www.novaquatis.eawag.ch). For diffuse sources, some practical consequences like a change towards less mobile biocides for facade protection can rapidly be implemented, but this is not the case for the more systemic changes of source separation of wastewater streams. The inflexibility of the present sewer-based wastewater treatment system (discussed in detail by Larsen and Gujer, 2001) prohibits rapid changes and such fundamental changes to the system demand profound reflection within the community of wastewater professionals. For dry sanitation concepts, urine source separation is already implemented in some full scale projects for better handling of feces (e.g. in China and South Africa). However, this normally takes place without concomitant installation of adequate process engineering technologies for nutrient removal or recycling (Bhagwan et al., 2008). Due to the high pressure for finding practical solutions to this problem, the developing world may well serve as the 'frontier', where advanced nutrient management technologies for urine will be able to mature (see also http://www.eawag.ch/vuna).

\section{RESOURCES IN URBAN WATER MANAGEMENT: A COMPREHENSIVE CONCEPT}

There is a tendency that resources of urban water management are considered in isolation, as illustrated by the different conference labels 'energy', 'ecosan' (for nutrient recycling), 'REUSE' (of water), etc. As a result of this fragmented focus, it is difficult to find solutions with optimal efficiency. Figure 1 illustrates comprehensively the resources involved in urban water management (for a more thorough discussion, see Larsen and Gujer, 1997). In a more comprehensive approach, all types of resources will be taken into account. At our present level of understanding this would in general terms mean that the technologies will be able to physically handle water scarcity and recycle phosphorus, they will be energy efficient, and provide sufficient protection of receiving waters and the atmosphere. Furthermore, the solutions shall fulfill the economic and financial requirements of the community in question, and be accepted and implemented by the population.

\begin{tabular}{l|r} 
1. IN WASTEWATER \\
Water \\
Energy \\
Chemicals, etc.
\end{tabular} \begin{tabular}{r} 
2. FOR HANDLING \\
Energy \\
\hdashline Chemicals, etc. \\
Receiving waters \\
Agricultural soil \\
Atmosphere, etc. \\
3. NATURAL
\end{tabular} $\begin{array}{r}\text { Capital } \\
\text { Institutions } \\
\text { 4. Acceptance, etc. }\end{array}$

Figure 1 A comprehensive overview of the resources involved in urban water management. Adapted from Larsen and Gujer (1997), where resources are defined as the 'means for action'.
Whereas receiving waters (3) and capital (4) were considered the central resources in the last century, we now see an increasing interest in the resources of type (1) and (2). For the natural resources (3), the atmosphere becomes more important, and for the anthropogenic (4), acceptance gains importance. Obviously, this shift is motivated by scarcity: Water scarcity, finite phosphorus resources, and the overloading of the atmosphere with greenhouse gases are severe problems, which call for new concepts and perhaps even a new paradigm, with implications for households. 


\section{LESSONS LEARNED FROM THE PRESENT SYSTEM}

As discussed in detail by Borsuk et al. (2008), it is difficult to compare the resource efficiency of different concepts, e.g with an LCA or MCDA approach - such comparisons can only be made for specific technologies. It is thus hardly possible to know in advance whether a new paradigm - in this case source control and source separation - will be more resource efficient than the existing one. Even if we could account for all physical resources involved, there is always the open question of costs and for technologies entering private households, the question of user acceptance and compliance. One way of overcoming this problem is to look at important developments of the existing system, which may help to understand whether and how such changes are necessary and possible.

The never ending story of wastewater management. Despite a century of development, end-of-pipe wastewater treatment seems to expand at an ever increasing pace. Starting with primary sedimentation in the first half of the last century, secondary treatment came up prominently in the second half, followed by tertiary treatment: phosphorus removal, nitrification and denitrification. In the previous decades, micropollutants have taken over the role as 'emerging problem', but phosphorus recovery, anaerobic sewers, and energy issues may soon prove even more prominent (see Cordell et al., 2009 on 'peak phosphorus'; Ablin and Kinshella, 2004 for an example of anaerobic sewers, and Kenway et al. (subm.) for a review on energy in urban water management). With increasing complexity, solutions to a newly recognized problem tend to lead to new difficulties, calling for ever more advanced and resource consuming technology. In Table 1, a number of contemporary problems are listed, with a typical solution and some follow-up problems arising from the solutions.

Table 1 Typical contemporary issues and their follow-up problems

\begin{tabular}{|c|c|c|}
\hline Original Problem & Solution & Follow-up Problems \\
\hline Water scarcity & $\begin{array}{l}\text { Water saving } \\
\text { Decentralized wastewater recycling } \\
\text { Centralized wastewater recycling }\end{array}$ & $\begin{array}{l}\text { Anaerobic sewers } \\
\text { Anaerobic sewers } \\
\text { Problems of public acceptance and/or high } \\
\text { costs for second pipe system }\end{array}$ \\
\hline$P$ in receiving waters & $\begin{array}{l}\text { Chemical P-removal } \\
\text { Biological P-removal }\end{array}$ & $\begin{array}{l}\text { Rising costs of precipitation agents; sludge } \\
\text { handling; difficulties of } P \text { recycling } \\
\text { High demand for readily degradable COD }\end{array}$ \\
\hline $\begin{array}{l}\text { Nitrogen in receiving } \\
\text { waters }\end{array}$ & Nitrification/Denitrification & $\begin{array}{l}\text { High demand for readily degradable COD } \\
\text { Large plants to prevent } \mathrm{N}_{2} \mathrm{O} \text { emissions }\end{array}$ \\
\hline Phosphorus depletion & Recovery from sludge & Bio-P plants are of advantage \\
\hline Anaerobic sewers & Dosing of nitrate & Energy consumption; removal of COD \\
\hline Lack of $\mathrm{COD} \rightarrow \mathrm{N}_{2} \mathrm{O}$ & Dosing of methanol & Energy consumption; sludge production \\
\hline
\end{tabular}

Single-step optimization may lead to sub-optimal solutions from a resource point of view. Although from a process engineering point of view, the problems in Table 1 seem manageable, this will always be at a cost. One good example is the occurrence of anaerobic sewers due to climate change and water scarcity. In a case study of Phoenix described by Ablin and Kinshella (2004), it is argued that high temperatures, lack of metals in the wastewater (due to source control), long travel times, and high organic concentrations favor hydrogen sulfide production in sewers - all conditions that we expect will increase in the future. In Phoenix, the satellite water reclamation plants are blamed for increasing organic concentration and reducing water velocity in the sewers. The addition of nitrate is an obvious measure for preventing sulfide production. However, the production of nitrate is energy consuming and the dosing of nitrate will lead to more COD removal in the sewers (Mohanakrishnan et al., 2009). Due to diurnal variation in COD loading, a complex dosing system is necessary to avoid over dosage of nitrate (Mohanakrishnan et al., 2009). At treatment plants with tertiary treatment, a lack of COD will lead to incomplete dentrification with a high probability of increased 
$\mathrm{N}_{2} \mathrm{O}$ emissions, a greenhouse gas about 300 times more potent than $\mathrm{CO}_{2}$ (on a 100 year horizon; see Kampschreur et al., 2009 for a discussion of denitrifying conditions leading to $\mathrm{N}_{2} \mathrm{O}$ emissions). In order to prevent $\mathrm{N}_{2} \mathrm{O}$ emissions, methanol addition will probably be recommended, which again leads to a high consumption of energy and increased sludge production (Purtschert et al., 1996). If sewer and treatment plant are optimized independently, all these interventions may well be justifiable: In the first step, saving expensive sewers will be a strong argument for increased resource consumption, and in the second step, nitrate and especially $\mathrm{N}_{2} \mathrm{O}$ emissions from treatment plants will easily justify the use of methanol. Only if the entire system is considered concomitantly, it may be realized that the problems could be better solved at the source. One possibility would be the local nitrate production from source separated urine (Jiang et al., 2010), but it would be prudent to investigate first the possible $\mathrm{N}_{2} \mathrm{O}$ emissions from denitrification in sewers (although $\mathrm{N}_{2} \mathrm{O}$ emissions are probably more prominent under nitrifyinig than under denitrifying conditions, at least at high concentrations of readily available COD; Keller and Yang, 2010). Where anaerobic sewers are caused primarily by sediments (due to water saving or reuse and high temperatures), it could be worth while to reconsider the rationale of sewer transport of feces in warm, water scarce areas. There are good chances that with modern technology, superior concepts for feces handling at the source can be found (for a discussion, see Larsen and Maurer, in press).

From a global point of view, advanced wastewater treatment (nutrient elimination) has not been successful. During the previous decades, much wastewater related research has been devoted to nutrient elimination, with only a small global impact (Figure 2). See Galloway et al. (2008) for a review of the compelling evidence of the detrimental global effects of nitrogen.
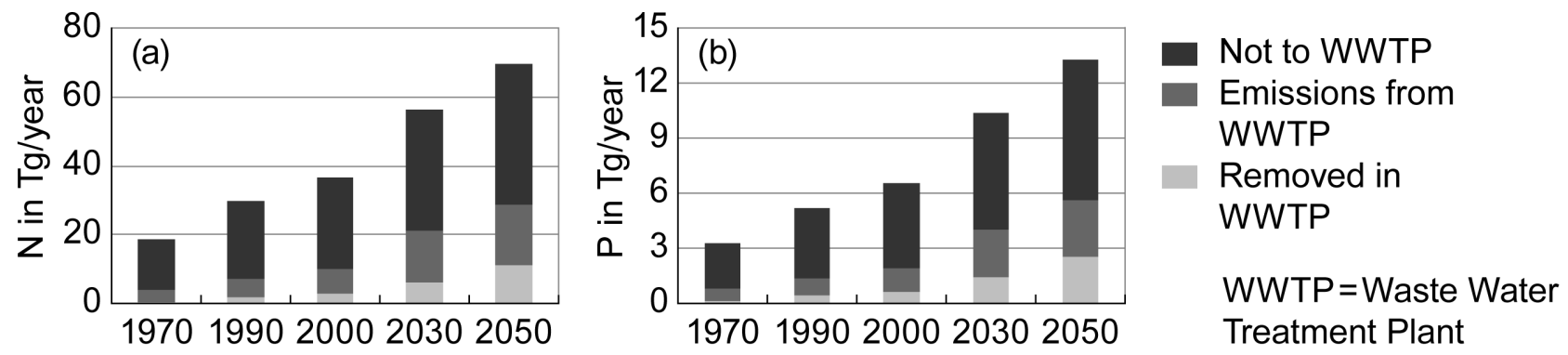

Figure 2 Global wastewater nitrogen (a) and phosphorus (b) management. Based on Van Drecht et al., 2009. Values for 2030 and 2050 are average forecasts for four global socio-economic scenarios.

From Figure 2 it is seen that even if the global removal of $\mathrm{N}$ and $\mathrm{P}$ in centralized wastewater treatment plants is assumed (optimistically) to quadruple from year 2000 to year 2050, the total emissions will still nearly double within the same period of time. The reason is a predicted drastic increase in wastewater related $\mathrm{N}$ - and $\mathrm{P}$ - emissions due to population growth and better nutrition. Nearly two thirds of the $\mathrm{N}$ and $\mathrm{P}$ emissions in 2050 are predicted to stem from people not served by any treatment plant at all (Figure 2). It is thus not surprising that the authors (Van Drecht et al., 2009) discuss the potential of these emissions being returned to agriculture as fertilizers, as an alternative to diffuse emissions of nitrogen and phosphorus with unknown fate in the environment.

Measures at the source were efficient in the past. Today, there is a general understanding in the community of wastewater professionals that non-degradable detergents and heavy metals are better eliminated at the source than in a treatment plant. This was not always so: the first ideas were based on end-of-pipe measures (e.g. destroying foam in the treatment plants). A better documented example is the phosphate ban in detergents, implemented in Switzerland as early as 1986, which led to lower P loads in wastewater treatment plants. This measure was only accepted and implemented after a tedious debate, but it proved even more efficient than anticipated (for a discussion, see Siegrist and Boller, 1999). These examples show that the acceptance of new ideas may take time. 


\section{SOURCE SEPARATION AND RESOURCE EFFICIENCY}

Several authors have shown that for implementation of wastewater related source separation, optimal resource allocation depends on the specific technology choice (e.g. Lundin et al., 2000; Remy and Jekel, 2008). Energy consumption, for example, does not only depend on the concept, but also on the specifications of the actual technology. This was also illustrated by a multi criteria decision analysis (MCDA) of different urine source separation technologies for a specific Swiss setting (Borsuk et al., 2008): Large uncertainties with respect to energy efficiency and costs considerably blurred the results, and the lack of acceptable toilet technology stopped the implementation of a NoMix full scale project. I will thus argue with specific examples, and in this section, at least one example from each type of resources is discussed.

Example from Resource Type 1: Nutrient recovery. Nutrients from wastewater can be recovered for use in agriculture or in industry. Today, two thirds of the wastewater related nutrients originate from areas without wastewater treatment plants, whereas this number is predicted to shrink to about $50 \%$ in 2050 (Figure 2). Most of the nutrients in wastewater are found in toilet waste (about $80 \%$ of $\mathrm{N}$ and $50 \%$ of P; Larsen et al., 2009). For direct recycling of nutrients via wastewater, treatment is required for hygienic reasons (WHO, 2006), whereas recycling of properly treated wastewater depends more on the proximity of sufficient agricultural land to take up the nutrients. From the point of view of nutrient recovery, it would be an advantage to separate the concentrated toilet waste from the bulk amount of water, especially in areas without treatment plants and in urban areas where long transport distances prohibit direct use of wastewater in agriculture. Today, it is possible to treat urine and feces sufficiently in order to use both items directly in agriculture (see e.g. Nordin et al., 2009), and a large number of processes are in development for reducing the volume of urine (Maurer et al., 2006; Udert and Wächter, 2010). For phosphorus, spreading of sewage sludge is possible, but only the organic bound phosphorus in sludge is available for plant growth (Römer, 2006). In some European countries, sludge is not well accepted in agriculture, most notable in Switzerland, where its use is prohibited (Lienert and Larsen, 2007).

Example from Resource Type 2: Energy. A large part of the energy used in a treatment plant is due to nitrification (mainly increased aeration for oxidation of ammonia). Furthermore, for denitrification, pumping energy is required, and with a high SRT, less energy is generated from anerobic treatment of sewage sludge. In a modeling study, Wilsenach and van Loosedrecht (2006) showed that replacing conventional nitrification /denitrification of wastewater by partial nitrification and autotrophic denitrification of nitrogen in urine could save a considerable amount of energy. In the case of anaerobic sewers, local nitrification of urine would be an energy-efficient alternative to the dosing of external nitrate. Whether it will be energy efficient to recycle nitrogen from urine remains to be seen in practice, but the chances are good. Maurer et al. (2003) showed that it is possible, but still takes some technical optimization. One interesting aspect of nitrogen recycling would be the general reduction in nitrogen production, proposed by many authors, e.g. Galloway et al. (2008). Less nitrogen production in the first place would prevent unintended environmental side effects from the nitrogen cascade.

Example from Resource Type 3: Water pollution control. In Table 2, the effectiveness of nutrient elimination of different technologies is compared. The source separating example chosen is NoMix technology (urine source separation). It is easily seen that urine source separation compares well with modern tertiary wastewater treatment with respect to nitrogen management, and that in combination with a phosphate ban in detergents, it is also very effective with respect to phosphorus management. Since the major strength of urine source separation is nitrogen removal, it combines 
well with simple wastewater treatment technologies, which are much more prevalent than tertiary treatment (nearly four times more people have access to secondary treatment than to tertiary treatment; Green et al., 2004). Even as 'stand-alone-technology' or combined with simple feces management, NoMix technology is quite effective for water pollution control in areas where nutrients are of major concern.

Table 2 Comparison of estimated elimination efficiencies [\%] of wastewater treatment plants (WWTP) versus NoMix technology. We only consider domestic wastewater and assume $5 \%$ loss of raw wastewater in combined sewers overflow, $100 \%$ connection, and European standards. Adapted from Larsen et al., 2007.

\begin{tabular}{|c|c|c|c|c|}
\hline & \multicolumn{3}{|c|}{ Typical removal efficiencies (\%) } & \multirow{2}{*}{$\begin{array}{l}\mathrm{NH}_{4}{ }^{+} \text {effluent } \\
\text { concentration }\end{array}$} \\
\hline & COD & $\mathrm{N}$ & $P$ & \\
\hline WWTP, primary treatment & 30 & 5 & $5-15$ & High \\
\hline WWTP, chemical precipitation & $60-75$ & $15-30$ & $85-95$ & High \\
\hline WWTP, SRT 2 days & 75 & 25 & $15-85$ & High \\
\hline WWTP, SRT 8-10 days & 90 & 25 & $15-85$ & Low \\
\hline WWTP SRT > 12 days & 90 & $50-75$ & $15-85$ & Low \\
\hline WWTP, SRT / 12 days + external carbon & 90 & 85 & $15-85$ & Low \\
\hline WWTP + P-filter ${ }^{(*)}$ & & & $>85$ & \\
\hline NoMix technology (90 \% separation efficiency) & 15 & $70-80$ & $15-50$ & Low \\
\hline
\end{tabular}

(*) only information of $\mathrm{P}$ in effluent is given; SRT = Solids Retention Time

Example from Resource Type 4: Public acceptance and cost. Traditionally, costs have been the only anthropogenic resource considered of importance. Today, it is increasingly recognized that also 'softer' issues like acceptance and compliance will play a role. For all practical purposes it is thus productive to consider these 'softer' issues at the same level as the more conventional resources. For sanitation technologies entering households, acceptance and compliance are necessary 'resources' that need to be considered in order to reap the environmental gains potentially offered by these technologies. As an example, the best water saving shower will not show any environmental effect if the water saving is fully compensated by longer showers (for differentiated discussion of the relationship between technology and society, see e.g. Paradis, in press). For the practical purpose discussed in this paper, the main questions to ask are thus (1) 'do people accept the concept of source separation?' and (2) 'under which circumstances do people accept actual source separating technology?' For the simplified discussion in this paper, we assume that acceptance and compliance are positively correlated (see Lienert and Larsen, 2010 for a discussion of the data on this issue). Due to space limitations, only the acceptance of urine source separation in flush toilets will be presented here (for an overview of the available literature on acceptance of different source separating measures, see Larsen and Maurer, in press). Considerable efforts have been devoted to this issue, but most of the literature is only available in Swedish and the studies are of varying quality. However, there are clear trends. These are reported in a review of acceptance surveys from 38 projects on urine source separation (in flush toilets) in 7 European countries with a total of 2700 respondents (Lienert and Larsen, 2010). All persons questioned had access to urine source separating flush toilets. Around $80 \%$ of users liked the idea generally and were satisfied with the level of bathroom comfort in the projects where they were exposed to the technology. $85 \%$ considered urine-fertilizers a good idea, and 70\% would purchase food fertilized with a urine based product. Despite the high level of general acceptance, $60 \%$ of users had problems with the practical 
use of the toilet, and in the review it is concluded that urine source separation toilet technology needs improvement. There was little difference between countries, but in private settings people were considerably more critical than in public settings. Where farmers are concerned, one of the most critical issue is the fear of organic micropollutants, which could lead to the agricultural products being rejected by the public (see also Lienert et al., 2003).

Although public acceptance is central for any wastewater related technology affecting people directly, e.g. in their own household, only economically competitive source separating technologies will have a chance in practice. Prototypes applied today are mostly too expensive to compete with existing end-of-pipe technology, and only mass production will be able to reduce prices (Störmer et al., 2010). Maurer et al. (2005) estimated at which investment source separating technologies would achieve a break-even with conventional technology. For urine source separation, this break-even was at that time found to be at around 260-440 US\$ per person, assuming a 15 years lifetime of NoMix technology and similar costs of maintenance as today. The costs were considered realistic under the condition of mass production, but minimizing maintenance efforts will be challenging.

\section{DISCUSSION AND CONCLUSION}

In rich countries with high water consumption, centralized end-of-pipe wastewater treatment has been very successful in providing the local services of urban water management. Based on this experience, there is a general expectation that this same technology will be able to solve the severe global water problems. This is not plausible. On a global scale, the environmental effects of wastewater treatment, especially tertiary treatment, has been small and even with optimistic assumptions, they will stay small in the future. With increasing pressure on water and other resources, centralized end-of-pipe wastewater treatment becomes more and more complex, and different measures start to counteract each other. There is ample evidence that source separating technologies hold a large potential for resource efficiency, but this potential will not materialize without a much greater effort on research and development - not only in the area of engineering, but also with respect to the socio economic dimensions. As discussed by Störmer et al., 2010, further critical areas that need considering are regulation, suitable governance and management models, and the involvement of industrial partners. High uncertainty is a major obstacle for innovations, but should not be an argument for not pursuing developments with a high potential benefit for the global environment.

\section{REFERENCES}

Ablin R. L. and Kinshella P. (2004). DUDE, where's my pipe - Accelerated corrosion rate threatens Phoenix sewers. In: Proceedings of the ASCE Pipeline Division Specialty Congress - Pipeline Engineering and Construction, 2004, 843-850.

Bhagwan J. N., Still D., Buckley C. and Foxon K. (2008). Challenges with up-scaling dry sanitation technologies. Water Sci. Technol., 58 (1), 21-27.

Borsuk M. E, Maurer M., Lienert J. and Larsen T. A. (2008). Charting a path for innovative toilet technology using multicriteria decision analysis. Environ. Sci. Technol., 42 (6), 1855-1862.

Burkhardt M., Kupper T., Hean S., Haag R., Schmid P., Kohler M. and Boller M. (2007). Biocides used in building materials and their leaching. Wat. Sci. Technol., 56 (12), 63-67.

Cordell D., Drangert J. O. and White, S. (2009). The story of phosphorus: Global food security and food for thought. Global Environ. Change, 19 (2), 292-305.

Galloway J. N., Townsend A. R., Erisman J. W., Bekunda M., Cai Z., Freney J. R., Martinelli L. A., Seitzinger S. P., Sutton M. A. (2008). Transformation of the nitrogen cycle: recent trends, questions, and potential solutions. Science, 320, 889-892.

Green P. A., Vörösmarty C. J., Meybeck M., Galloway J. N., Peterson B. J. and Boyer E. W. (2004). Pre-industrial and contemporary fluxes of nitrogen through rivers: a global assessment based on typology. Biogeochemistry, 68, 71-105.

Guest J. S. and 15 further authors (2009). A new planning and design paradigm to achieve sustainable resource recovery from wastewater. Environ. Sci. Technol., 43 (16), 6126-6130. 
Jiang F., Chen Y., Mackey H. R., Chen G. H. and van Loosdrecht M. C. M. (2010). Urine nitrification and sewer discharge to realize in-sewer denitrification to simplify sewage treatment in Hong Kong. Proceedings of the 7th IWA Leading-Edge Conference on Water and Wastewater Technologies, 2-4 June 2010, Phoenix (AZ), USA.

Kampschreur, M. J., Temmink, H., Kleerebezem, R., Jetten, M. S. M. and van Loosdrecht, M. C. M. (2009). Nitrous oxide emissions during wastewater treatment. Water Res., 43, 4093-4103.

Keller J. and Yuan Z. (2010). Wastewater treatment and greenhouse gas emissions. Proceedings of the 7th IWA Leading-Edge Conference on Water and Wastewater Technologies, 2-4 June 2010, Phoenix (AZ) USA.

Kenway S. J., Lant P. A, Priestley A., Daniels P. (subm.). The connection between water and energy in cities, a review. Subm. to Wat. Sci. Technol.

Larsen T. A., Alder A. C., Eggen R. I. L, Maurer M. and Lienert J. (2009) Source separation: Will we see a paradigm shift in wastewater handling? Environ. Sci. Technol., 43 (16), 6121-6125.

Larsen T.A. and Gujer W. (1996) Separate management of anthropogenic nutrient solutions (human urine). Water Sci. Technol., 34 (3-4), 87-94.

Larsen T. A. and Gujer W. (1997). The concept of sustainable urban water management. Water Sci. Technol., 35 (9), 3-10.

Larsen T. A. and Maurer M. (in press). Source Separation and Decentralization. In: Wilderer (ed.) Treatise on Water Science. Elsevier. ISBN 13: 978-0-444-53193-3.

Larsen, T. A. and Gujer, W. (2001). Waste design and source control lead to flexibility in wastewater management. Water Sci. Technol. 43(5), 309-317.

Larsen T. A., Maurer M., Udert K. M. and Lienert J. (2007). Nutrient cycles and resource management: implications for choice of wastewater treatment technology. Water Sci. Technol., 56 (5), 229-237.

Larsen T. A., Peters I., Alder A., Eggen R., Maurer M. and Muncke J. (2001). Re-engineering the toilet for sustainable wastewater management. Environ. Sci. Technol., 35 (9), A192-A197.

Lienert J., Haller M., Berner A., Stauffacher M. and Larsen T. A. (2003). How farmers in Switzerland perceive fertilizers from recycled anthropogenic nutrients (urine). Water Sci. Technol., 48 (1), 47-56.

Lienert J. and Larsen T. A. (2010). High acceptance of urine source separation in seven European countries - a review. Environ. Sci. Technol., 44 (2), 556-566.

Lienert J. and Larsen T. A. (2007). Soft paths in wastewater management - the pros and cons of urine source separation. Gaia, 16 (4), 280-288.

Lundin M.; Bengtsson M. and Molander S. (2000). Life cycle assessment of wastewater systems: influence of system boundaries and scale on calculated environmental loads. Environ. Sci. Technol., 34 (1), 180-186.

Maurer M., Pronk W. and Larsen T. A. (2006). Treatment processes for source-separated urine. Water Res., 40, $3151-3166$.

Maurer M., Rothenberger D. and Larsen T. A. (2005). Decentralised wastewater treatment technologies from a national perspective: At what cost are they competitive? Water Sci. Technol.: Water Supply, 5 (6), 145-154.

Maurer M., Schwegler P. and Larsen T. A. (2003). Nutrients in urine: energetic aspects of removal and recovery. Water Sci. Technol., 48 (1), 37-46.

Mohanakrishnan J., Gutierrez O., Sharma K. R., Guisasola A., Werner U., Meyer R. L., Keller J. and Yuan Z. (2009). Impact of nitrate addition on biofilm properties and activities in rising main sewers. Water Res., 43, 4225-4237.

Nordin A., Nyberg K. and Vinneras B. (2009). Inactivation of Ascaris eggs in source-separated urine and feces by ammonia at ambient temperatures. Appl. Environ. Microbiol., 75 (3), 662-667.

Paradies E. (in press). Sustainability transitions and the nature of technology. Found. Sci., doi:10.1007/s10699-010-9197-4.

Purtschert I., Siegrist H. and Gujer W. (1996). Enhanced denitrification with methanol at WWTP Zurich-Werdholzli. Water Sci. Technol., 33 (12), 117-126.

Remy C. and Jekel M. (2008). Sustainable wastewater management: life cycle assessment of conventional and source-separating urban sanitation systems. Water Sci. Technol., 58 (8), 1555-1562.

Römer W. (2006). Plant availability of P from recycling products and phosphate fertilizers in a growth-chamber trial with rye seedlings. J. Plant Nutr. Soil Sci., 169 (6), 826-832.

Shannon M. A., Bohn P. W, Elimelech M., Georgiadis J. ., Mariñas B. J., Mayes A. M. (2008). Science and technology for water purification in the coming decades. Nature, 452, 301-310.

Siegrist H. and Boller M. (1999). Auswirkungen des Phosphatverbots in den Waschmitteln auf die Abwasserreinigung in der Schweiz (Consequences of the phosphate ban in detergents on wastewater treatment in Switzerland). Korrespondenz Abwasser, 46 (1), 57-65 (in German).

Störmer E., Binz C. and Truffer B. (2010). Globale Herausforderung für die Siedlungswasserwirtschaft. Ein Roadmapping für dezentrale Wassertechnologien im Jahr 2020 (Global challenge for urban water management. A roadmapping for decentralized water technologies in the year 2020). Technikfolgenabschätzung - Theorie und Praxis, 19 (1), 40-48 (in German).

Udert K. M. and Wächter M. (2010) Complete nutrient recovery from source-separated urine. Proceedings of the 7th IWA Leading-Edge Conference on Water and Wastewater Technologies, 2-4 June 2010, Phoenix (AZ), USA.

UN Documents (1992). The Dublin statement on water and sustainable development. International Conference on Water and the Environment in Dublin, Ireland, 1992. http://www.un-documents.net/h2o-dub.htm (assessed 29 November 2010) 
Van Drecht G., Bouwman A. F., Harrison J., Knoop J. M. (2009). Global nitrogen and phosphate in urban wastewater for the period 1970 to 2050. Glob. Biogeochem. Cycle, 23, GB0A03, doi:10.1029/2009GB003458.

WHO (2006). Guidelines for the safe use of wastewater, excreta and greywater. Vol 2 - wastewater use in agriculture. World Health Organization, ISBN 9241546867.

Wilsenach J. A. and van Loosdrecht M. C. M. (2006). Integration of processes to treat wastewater and source-separation. J. Environ. Eng.-ASCE, 132 (3), 331-341. 